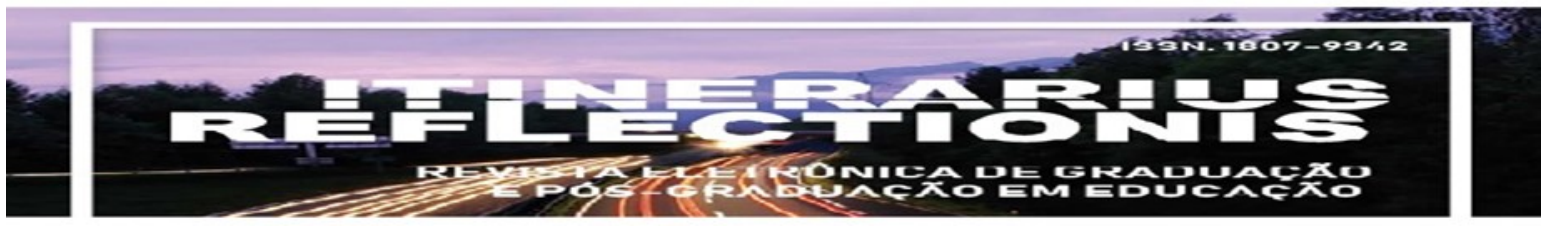

Volume 15, número 1, ano 2019.

\title{
TRADUTOR (A) INTÉRPRETE DA LÍNGUA BRASILEIRA DE SINAIS: diferentes caminhos no processo de tradução-interpretação
}

\author{
Érica Ferreira Melo ${ }^{1}$ \\ Cristiane de Fátima Lemes Domingos ${ }^{2}$
}

Resumo: O objetivo da pesquisa consiste em compreender o trabalho do tradutor (a) intérprete de língua brasileira de sinais (TILS/Libras), durante a realização do processo de tradução-interpretação. De forma específica buscamos refletir sobre as atribuições deste profissional a partir do código de ética e da legislação que ampara esta profissão, bem como salientar os processos e estratégias durante o referido processo. Para alcançar estes objetivos nos ancoramos nos pressupostos teórico-metodológicos da pesquisa qualitativa, orientados pelo apoio bibliográfico de Gesser (2011), Lacerda (2010), quadros (2004), entre outros que discutem as questões em torno desta temática. Pautamos também no código de ética e na legislação que regulamenta o trabalho da referida profissão. As questões discutidas nesse artigo possibilitam a compreensão do trabalho do TILS. Além das atribuições profissionais, destacamos a contribuição do referido profissional na luta pelo reconhecimento e valorização da libras e da cultura surda. As ponderações propostas no decorrer deste artigo nos convidam a pensar e refletir sobre a tomada de decisões no dia-a-dia do trabalho desse profissional.

Palavras-chave: Tradução e interpretação. Língua Brasileira de Sinais. Processos e estratégias do tradutor intérprete de Libras.

\section{TRANSLATOR (A) INTERPRETER OF THE BRAZILIAN LANGUAGE OF SIGNS: different paths in the translation-interpretation process}

\begin{abstract}
The objective of the research is to understand the work of the translator/interpreter of Brazilian sign language (TILS / Libras) during the translation-interpretation process. Specifically, we seek to reflect on the attributions of this professional based on the code of ethics and the legislation that supports this profession, as well as highlighting the processes and strategies during that process. In order to reach these objectives, we anchor ourselves in the theoretical-methodological assumptions of the qualitative research, guided by the bibliographic support of Gesser (2011), Lacerda (2010), Quadros (2004), among others that discuss the issues around this theme. We base also on the code of ethics and the legislation

\footnotetext{
1 Mestre em Educação pela Universidade Federal de Viçosa (2013) - Linha de Pesquisa: Educação, Estado e Sociedade. Especialista em Educação Infantil (2010) e graduada em Pedagoga pela Universidade Federal de Goiás (2008). Atuou com pesquisadora do Programa CAPES/INEP, titulado: Observatório da Educação do Campo - Práticas em Educação de Jovens e Adultos, Letramento e Alternâncias Educativas, Núcleo em Rede UFV / UEMG / UFSJ. Tem experiência na área de Educação, com ênfase em coordenação pedagógica, educação do campo, inclusão e movimentos sociais. Possui proficiência em LIBRAS emitida pelo Centro de Capacitação de Profissionais de Educação e de Atendimento às Pessoas om surdez (CAS) (2016-2021).

${ }^{2}$ Universidade Federal de Goiás/REJ.
} 
that regulates the work of said profession. The issues discussed in this article make it possible to understand the work of TILS. In addition to the professional attributions, we highlight the contribution of this professional in the struggle for recognition and appreciation of Libras and deaf culture. The weights proposed in the course of this article invite us to think and reflect on the decision-making in the day-to-day work of this professional.

key-words: Translation and interpretation. Brazilian Language of Signals. Processes and strategies of the interpreter of Libras.

\section{INTRODUÇÃO}

$\mathrm{O}$ (a) tradutor(a) e intérprete de Língua Brasileira de Sinais/Português (TILS/Libras) consiste no profissional que realiza a intermediação da língua portuguesa (oral e/ou escrita) para a Libras (visio-gestual e/ou escrita) e da Libras para a Língua portuguesa. Quadros (2004) ressalta que tal profissional realiza o processo de tradução e interpretação ${ }^{3}$, o qual consiste em contemplar a mensagem original em suas especificidades, bem como respeitar os detalhes da língua de chegada. Assim, de acordo com Gesser (2011), o trabalho de traduçãointerpretação ultrapassa o domínio das duas línguas envolvidas, pois contempla também aspectos culturais, contextuais, linguísticos, técnicos e gramaticais.

Deste modo, ressaltamos que para realizar o processo de tradução e interpretação, o TILS precisa ter conhecimento prévio dos temas que serão interpretados, ter compreensão das questões em torno da cultura ouvinte, da cultura surda e do processo de ensino e aprendizagem dos surdos. Além disto, espera-se que o referido profissional compreenda os processos e estratégias para realizar a tradução e interpretação, com a finalidade de que as pessoas surdas participem e compreendam o conhecimento mediado pela língua de libras.

Entretanto, o processo histórico do trabalho desse profissional, presente em dados oficiais iniciou-se por volta dos anos de 1980, o que nos mostra que configura em uma profissão ainda em construção. Consequentemente, o debate em torno de seu trabalho e as posturas adequadas ainda é incipiente e muito polêmica. Nesse contexto, ao considerar a complexidade de seu trabalho e a profundidade de sua função, o objetivo da pesquisa consiste em compreender o trabalho dos TILS, durante a realização do processo de traduçãointerpretação. Especificadamente, buscamos, refletir sobre as atribuições para este profissional a partir do código de ética e da legislação que ampara a profissão; salientar os processos e estratégias durante a tradução e interpretação da Libras.

\footnotetext{
${ }^{3}$ De acordo com Gesser (2011), de forma sucinta, a diferenciação entre tradução e interpretação consiste na seguinte: A interpretação envolve línguas orais, já a tradução envolve no mínimo uma língua escrita.
} 
Para alcançar estes objetivos nós recorremos aos pressupostos teórico-metodológicos da pesquisa qualitativa, que conforme explica Minayo (1993, p.21): "Ela se preocupa, nas ciências sociais, com um nível de realidade que não pode ser quantificado. Ou seja, ela trabalha com o universo de significados, motivos, aspirações, crenças, valores e atitudes". Assim, tal abordagem, tem a finalidade de se comprometer com a realidade do contexto que será pesquisado, o que corresponde a um contexto mais profundo das relações, processos e fenômenos.

Conforme destaca Chizzotti (2003), além de não se comprometer apenas com dados variáveis, a pesquisa qualitativa propõe uma partilha entre pesquisador e os elementos que constituem o objeto de pesquisa. A referida partilha, na perspectiva do autor torna-se necessária para que o pesquisador possa compreender aspectos minuciosos da realidade própria do objeto, o qual está carregado de significados e relações, que serão interpretadas pelo pesquisador com auxílio de uma teoria explicativa.

A escolha da abordagem qualitativa se justifica pelo objetivo da presente pesquisa que propõe compreender o trabalho do TILS. Assim, o trabalho deste profissional trata-se de um objeto real, que precisa ser entendido de forma minuciosa e profunda e com a preocupação dos significados, ações e a valores envolvidos no processo de trabalho desse profissional.

No sentido de alcançar os seus objetivos, a pesquisa se constituiu em um estudo bibliográfico de obras Gesser (2011), Lacerda (2010), Quadros (2004), entre outros que discutem as questões em torno do processo de tradução e interpretação da Libras. Pautamos também no código de ética e na Legislação que regulamenta o trabalho da referida profissão.

Para tanto, percorreremos o seguinte caminho: Discorreremos sobre o código de ética e a Legislação que orientam e reconhecem o TILS, posteriormente, faremos uma reflexão em torno do trabalho do mesmo ressaltando as estratégias, os modelos e as decisões que podem ser seguidas durante o processo de tradução e interpretação. Por último, faremos uma reflexão sobre os diferentes contextos de trabalho do referido profissional.

Os pontos discutidos nesse artigo se tornam pertinentes por permitirem a compreensão em torno do trabalho do TILS; bem como a importância do mesmo na busca da valorização e reconhecimento das pessoas surdas e da construção de uma sociedade mais inclusiva.

\section{CÓDIGO DE ÉTICA E A LEGISLAÇÃO DO TILS}


A história do TILS se relaciona com a valorização e o reconhecimento dos movimentos sociais dos surdos. De acordo com Santos (2012) à medida que os surdos organizados em movimentos lutavam pelo reconhecimento da Libras, enquanto um direito linguístico, as diversas instituições sociais eram pressionadas a garantirem que os surdos participassem desses espaços, por meio da mediação do TILS.

Outro aspecto presente no início da trajetória do TILS, consiste no fato de que se constituiu, conforme ressalta Lacerda (2010), na informalidade e nas relações sociais, por meio de trabalhos voluntários, sem o status de uma profissão. Isto é, este profissional foi se construindo, mais nas trocas de experiência com a população surda e seus pares, do que por meio de uma formação específica.

A partir das lutas e algumas conquistas, o TILS, gradativamente, começou a delinear o seu trabalho e contexto profissional. Assim, Quadros (2004) afirma que o TILS se configura como um profissional que domina a língua de sinais e a língua falada, no caso específico do Brasil, a Libras ${ }^{4}$ e a língua portuguesa. A autora ressalta que este profissional processa a informação dada na língua fonte, faz escolhas lexicais, estruturais, semânticas e técnicas para se aproximar da língua alvo. Trata-se de um esforço contínuo com a finalidade de que a interpretação se aproxime ao máximo da mensagem original.

Nos dias atuais, das primeiras décadas do século XXI, são inúmeros contextos que podem solicitar o trabalho do profissional TILS, tais como: "na academia, na mídia, em conferências, repartições, sistema judiciário, instituições religiosas, hospitais (GESSER, 2011, p. 32)". Dentre os vários contextos de trabalho, Quadros (2004) e Gesser (2011) nos alertam que no contexto educacional a atuação deste ainda é maior. Entretanto, trata-se de um trabalho que ainda requer reflexões, pesquisas e debates, já que de acordo com Gesser (2011) a presença do TILS nesse espaço acarreta em mudanças organizacionais e pedagógicas, capaz de instaurar uma nova dinâmica interacional que envolve o educando, o referido profissional e o professor regente, além de toda a comunidade escolar, tais como os colegas e demais trabalhadores da instituição.

Nesse novo contexto educacional, Kelman (2005) realizou uma pesquisa com o objetivo de analisar o trabalho do TILS, a qual confirmou que a função deste não se restringe a uma mera interpretação. A autora encontrou a existência de 11 funções diferentes no cotidiano real de trabalho do profissional, são elas:

\footnotetext{
${ }^{4}$ Ao contrário que muitas pessoas pensam a língua de sinais não é universal, pois, não existe um código simplificado apreendido e ensinado a todos os surdos do mundo inteiro, cada país possui sua própria língua de sinais (GESSER, 2009).
} 
1- Ensinar língua portuguesa para o surdo como segunda língua;

2- Ensinar Libras para o surdo como primeira língua;

3- Ensinar Libras para os ouvintes - alguns (as) colegas, professores (as) e funcionários (as);

4- Ajudar na adaptação curricular;

5- Participar do planejamento das aulas;

6- Integrar com o (a) professor (a) regente;

7- Orientar as habilidades de estudos das pessoas surdas;

8- Estimular a autonomia das pessoas surdas;

9- Proporcionar uma integração entre os surdos e os colegas;

10-Fazer o uso da comunicação multimodal;

\section{1- Promover a tutoria.}

A pesquisa de Kelman (2005) apresenta várias funções diferentes do TILS que atuam no contexto educacional das escolas. Assim, inúmeros trabalhos pedagógicos que ultrapassam o seu trabalho de tradução e interpretação e que geralmente, se confunde até mesmo com o trabalho do professor regente da sala de aula. Entretanto, conforme nos alerta Quadros (2004), o trabalho do TILS consiste em mediar a fala oral para a sinalizada e vice-versa, ele não é o responsável pelo processo de ensino-aprendizagem do educando surdo, ou seja, não pode ser confundido com o professor regente.

Com essa gama de funções, Gesser (2011) ressalta que é preciso refletir urgentemente sobre o jogo de tensões e a complexidade que os TILS precisam lidar diariamente. Trata-se de uma sobrecarga física, emocional, mas, acima de tudo profissional.

Nesse contexto, Lacerda (2010), nos alerta sobre a necessidade de que o TILS que trabalha no campo educacional tenha uma formação que enfatize as questões deste campo. Todavia, sabemos que a muitos destes profissionais se forma na prática, na troca de experiência com os seus pares e em cursos básicos e técnicos. Isto é, muitos profissionais ainda não possuem uma formação na área da educação, muito menos, na área de tradução e interpretação, uma vez que a primeira graduação em Letras - Libras, no Brasil se iniciou em $2006^{5}$, em torno de um pouco mais de uma década, o que historicamente, ainda trata-se de um curso recente.

\footnotetext{
5 “Em 2006, foi iniciado o primeiro curso de Letras Língua de Sinais Brasileira - Libras - no Brasil. A Universidade Federal de Santa Catarina está oferecendo o curso para formar professores de língua de sinais. [...] O programa selecionou 500 estudantes, sendo que 447 são surdos e 53 são ouvintes bilíngues. Esses estudantes estão espalhados em nove estados brasileiros (QUADROS; STUMPF, 2009, p. 169)
} 
Diante de tais questões, Quadros (2004) e Gesser (2011) ressaltam a importância de que o TILS oriente o seu trabalho por meio de alguns preceitos éticos, os quais correspondem ao código de ética, do Regimento Interno do Departamento Nacional de Intérpretes (FENEIS). Para tanto, o mesmo orienta que este profissional tenha algumas posturas adequadas, putadas na veracidade e fidelidade, que tenha caráter moral, que seja honesto, consciente e de equilíbrio emocional (QUADROS, 2004).

No que diz respeito ao ato de tradução e interpretação, de acordo com o código de ética, o TILS necessita ter uma atitude imparcial e neutra, ou seja, não deixar transparecer as suas opiniões pessoais, mas, sim a fidelidade da mensagem que está sendo interpretada. Cabe também a este profissional conhecer a sua própria competência, sendo este prudente em aceitar, ou não aceitar determinadas funções (IBID)

Em relação à vestimenta do TILS, o código de ética orienta que este tenha uma postura discreta, de modo a não chamar atenção mais para o seu próprio corpo do que para o trabalho de tradução e interpretação. Este profissional também precisa ser remunerado, de acordo com os seus direitos trabalhistas (IBID).

Ainda sobre o código de ética, este aponta a necessidade de que o TILS conheça as línguas envolvidas no processo de tradução e interpretação, além de conhecer as associações das pessoas surdas, envolver com os colegas intérpretes, demais professores. Porque, sempre que for possível, cabe a este profissional esclarecer questões em torno dos surdos e de sua cultura (IBID).

Além do código de ética do TILS, existe também a legislação que o ampara e o reconhece como profissional. Apesar da história da profissão do TILS ter início, no Brasil a partir dos anos de 1980, apenas 20 anos mais tarde, a legislação brasileira começou a fazer alusão a este profissional.Deste modo, a Lei 10.098, que estabelece normas gerais para a promoção da acessibilidade, em seu capítulo XII, referente aos sistemas de comunicação e sinalização, prevê a presença do TILS (BRASIL, 2000). Nele, de forma breve, vale ressaltar, que o poder público implementará a formação deste profissional, entretanto, sem uma descrição de como realizar tal formação, muito menos de como deverá ser organizado o seu trabalho.

Nos próximos anos, a lei 10.436 que regulamenta a Libras, como língua oficial da comunidade surda representou um grande avanço para o reconhecimento do TILS, pois, além de regulamentar a Libras também garantiu o atendimento aos surdos nas diversas instâncias sociais, tanto particulares quanto públicas (BRASIL, 2002). Esta Lei, não prevê a presença do 
intérprete, mas, o traz nas entrelinhas, visto que este profissional é que poderia mediar a comunicação entre os surdos e os ouvintes. Isto é, esta legislação começou a pressionar os diversos espaços sociais a contratarem tal profissional.

Já o Decreto 5.626, que regulamenta as leis citadas anteriormente, torna obrigatória a presença do TILS (BRASIL, 2005). Assim, o mesmo realiza uma descrição para a certificação destes profissionais que já trabalham e se formaram na prática, por meio do exame de proficiência em Libras, trata-se do PROLibras, que de acordo com Lacerda (2010) o objetivo deste exame se define por certificar e avaliar a fluência em Libras dos TILS, entretanto, a fluência em português, bem como as competências nas diferentes áreas do conhecimento não são avaliadas. Isto é, trata-se de uma certificação apressada de reconhecer a formação daqueles profissionais que já trabalham na área de tradução e interpretação.

Lacerda (2010) ressalta que o exame acontecerá anualmente, até que ocorra formação específica para os profissionais TILS em nível superior. Para a autora o Decreto 5.626 representa o embrião para os cursos superiores de tradução e interpretação em Libras. Apesar do Decreto 5.626 apresentar os vários lugares e momentos em que se torna necessária à presença do TILS, o mesmo não traz uma descrição, ou orientação de como precisa ser o trabalho desse profissional.

Apenas no ano de 2010, por meio da pressão de muitas lutas e uma sequência de Leis e Decretos foi sancionada a Lei 12.319 que regulamenta a profissão do TILS. Ela define as atribuições deste nos diversos espaços sociais, como mediador entre surdos e ouvintes. Além das atribuições, a referida Lei trata de questões éticas em seu trabalho, tais como: exercer a sua profissão com rigor técnico; respeito ao surdo e a sua cultura; zelar pela honestidade e descrição da informação, pelo trabalho livre de preconceito; postura e conduta adequadas ao ambiente e pela consciência de que a expressão é um direito (BRASIL, 2010).

No tocante, ao código de ética e a legislação em torno do trabalho de tradução e interpretação nos possibilita compreender que tal processo envolve um enorme empenho linguístico comunicativo por parte do TILS. Por essa via, ressaltamos a importância de que este profissional possa compreender os diferentes processos e estratégias no ato de tradução e intepretação, para que sejam possíveis escolhas éticas dentro desse processo, como desenvolveremos no próximo subitem.

\section{PROCESSOS E ESTRATÉGIAS NA TRADUÇÃO E INTERPRETAÇÃO DAS LÍNGUAS DE SINAIS}


Durante o processo de tradução e interpretação o TILS realiza um enorme empenho linguístico, o qual compreende tanto conhecimentos culturais e contextuais, quanto técnicos e gramaticais. Deste modo, Quadros (2004, apud ROBERTS,1992) apresenta seis competências esperadas desse profissional durante o processo de tradução e interpretação. Trata-se da competência linguística, de transferência, metodológica, na área, bicultural e técnica. Assim, para a autora, a competência linguística consiste em manipular e conhecer as duas línguas, no caso específico do Brasil ${ }^{6}$, a Libras e língua portuguesa. Quanto a transferência, ela se refere a transferir a mensagem de uma língua para outra, sem deixar de contemplar as especificidades de cada língua.

Quanto à metodológica se caracteriza por usar diferentes modos de interpretação e habilidades, com a finalidade de encontrar itens lexicais e terminologias adequadas. Em relação a competência na área, trata-se em compreender e dominar o conteúdo que está sendo interpretado (IBID).

A competência bicultural se refere em conhecer as culturas das duas línguas envolvidas. Enquanto a técnica consiste em posicionar-se adequadamente para realizar o trabalho de tradução e interpretação, ou seja, reconhecer e se apropriar dos aspectos linguísticos da Libras (IBID).

As competências apresentadas acima confirmam ainda mais a complexidade existente no processo de tradução e interpretação, em segundos, o TILS as realiza mentalmente, sem seguir necessariamente uma ordem de importância das competências. Deste modo, Gesser (2011) ressalta que esse processo não consiste em decodificar palavras em sinais e vice-versa, é preciso ter memória, tomada de decisão, categorização e estratégias de interpretação.

Com a finalidade de contribuir com algumas estratégias durante o processo de tradução e interpretação que acontece na maioria das vezes, de forma simultânea ${ }^{7}$, Quadros (2004) apresenta algumas propostas de modelos de processamento para o TILS, tratam-se dos modelos: cognitivo, interativo, interpretativo, comunicativo, sociolinguístico, processo de interpretação, bilíngue e bicultural. Segundo a autora, o modelo cognitivo corresponde em

Ao contrário que muitas pessoas pensam a língua de sinais não é universal, pois, não existe um código simplificado apreendido e ensinado a todos os surdos do mundo inteiro, cada país possui sua própria língua de sinais (GESSER, 2009).

${ }^{7}$ Dentre os processos de tradução e interpretação, gostaríamos de ressaltar os dois mais comuns, simultâneo e o consecutivo. No processo simultâneo a tradução e interpretação de uma língua para outra acontece simultaneamente ao tempo da enunciação. Enquanto no consecutivo o TILS, ouve (ou vê) e processa a mensagem, em uma determinada língua, para posteriormente realizar a passagem para a língua alvo (QUADROS, 2004). 
seguir três passos, em um primeiro momento o TILS entende a mensagem, internaliza o significado na língua alvo, para posteriormente expressar a mensagem na língua alvo sem comprometer a mensagem da língua fonte, como será apresentado no quadro a seguir:

Quadro 1- Modelo cognitivo

Mensagem original $>$ Recepção e compreensão $>$ Análise e internalização $>$ Expressão e avaliação $>$ Mensagem interpretada para a língua alvo

Fonte: Quadros (2004)

O modelo interativo, de acordo com Quadros (2004) aponta alguns elementos que podem afetar o processo de tradução e interpretação, tais como os participantes, o conteúdo da mensagem, o lugar, as interações entre os participantes, entre outros. Assim, a autora salienta que é preciso ponderar sobre estes elementos, bem como os fatores físicos do espaço, as decisões em nível lexical, sintático, semântico e o feedback da audiência, ou seja, a linguagem corporal, expressões faciais do público surdo.

No que se refere ao modelo interpretativo, o trabalho do TILS consiste em expressar fielmente, o sentido da mensagem da língua de partida (fonte) para a língua de chegada (alvo) (IBID). Já o modelo comunicativo tem como objetivo a transmissão da mensagem, como codificação entre as línguas. Nele o TILS consiste em um mero transmissor de informações, sem a responsabilidade de interação com o público surdo, durante a comunicação (IBID).

Outro modelo de processamento apresentado por Quadros (2004) consiste no sociolinguístico, no qual, o processo de tradução e interpretação se configura nas interações entre os sujeitos envolvidos. Assim, o TILS precisa reconhecer o contexto em que se realiza a comunicação, bem como, os participantes, os objetivos e a mensagem. Nesse modelo, conforme explicita a autora, torna-se necessário, que o TILS considere as seguintes categorias, conformo o quadro a seguir:

Quadro 2- Modelo sociolinguístico

- a recepção da mensagem;

- processamento preliminar (reconhecimento inicial);

- retenção da mensagem na memória de curto prazo (a mensagem deve ser retida em porções suficientes para então passar ao próximo passo);

- reconhecimento da intenção semântica (o intérprete adianta a intenção do falante);

- determinação da equivalência semântica (encontrar a tradução apropriada na língua); 
- formulação sintática da mensagem (seleção da forma apropriada);

- produção da mensagem (o último passo do processo da interpretação).

Fonte: Quadros (2004)

Quanto ao modelo do processo de interpretação, ele conta com a análise da mensagem da língua de partida (fonte), com o objetivo de compor a informação da língua de chegada (alvo). Neste modelo, o TILS precisa considerar a habilidade de compreender a mensagem; a organização do processo; a competência linguística das línguas envolvidas bem como, a cultura das mesmas; o conhecimento do TILS, ou seja, a experiência deste, sua formação profissional, seus hábitos e ambiente, seja ele físico, ou psicológico (IBID).

Em relação ao modelo bilíngue e bicultural, Quadros (2004) ressalta que neste modelo o TILS, precisa, essencialmente, levar em conta a sua postura e comportamento, no que diz respeito às línguas e culturas envolvidas no processo de tradução e interpretação. Cabe a este profissional definir o seu trabalho em cada contexto, ou seja, este profissional precisa ter autonomia em suas decisões.

Apesar de apresentar separadamente as peculiaridades dos modelos de processamento, compreendemos que existem alguns pontos em que estes se relacionam, ao ponto de nos confundir, sobre qual o modelo (s) utilizado (s). Nessa perspectiva, de acordo com Quadros (2004), independente do modelo contemplado, a essencialidade é atribuída mais ao sentido da mensagem, do que o significado de cada palavra, além disto, as culturas das línguas, no caso específico, Libras e a Língua portuguesa precisam ser levadas em conta, suas particularidades e diferenças. Outro ponto convergente dos modelos trata-se do período de duração da interpretação, um tempo extenso pode acarretar no cansaço físico e metal do TILS. Um tempo muito curto pode contribuir para que o profissional e a audiência não compreendam todo o contexto.

De acordo com Gesser (2011) os modelos apresentados contribuem para que o TILS compreenda e reflita sobre os caminhos e as técnicas para realizar o processo de tradução e interpretação. Compreendemos que como existem inúmeros contextos e espaços sociais que necessitam do trabalho do TILS, também existem diferentes modalidades de tradução e interpretação, cabe ao profissional escolher aquela (s) que combine, ou combinem com determinado contexto, ou ainda optar pela modalidade (s) que tem mais facilidade.

\section{CONSIDERAÇÕES FINAIS}


A legislação que orienta e reconhece o TILS, dispõe de forma sucinta o trabalho nas instituições de ensino e outros diferentes contextos. A mesma assegura que o surdo participe da informação e comunicação mediada pelo profissional TILS. Entretanto, a Lei por si só não garante grandes mudanças, torna-se necessário à articulação dos surdos organizados em movimentos sociais, bem como a articulação dos profissionais, para que o direito linguístico das pessoas surdas seja respeitado e valorizado; bem como a continuidade de pesquisas na área da tradução e interpretação das Libras, capazes de contribuir para a reflexão sobre a realidade do seu trabalho.

Estas pesquisas de acordo Rodrigues e Beer (2015) têm ampliado expressivamente. Os autores salientam que a presença do TILS em diversas esferas da sociedade, além dos pesquisadores interessados a investigar os processos tradutórios e interpretativos das línguas de sinais, entre outras questões tem contribuído para o reconhecimento e a celebração dos estudos de tradução e interpretação de línguas de sinais como um campo específico de conhecimento em expansão.

Apesar do TILS terem uma trajetória profissional, inicialmente marcada pela formação prática, o trabalho voluntariado e acontecer, geralmente, nos espaços religiosos, sem o status de uma profissão, estes paulatinamente, foram permeando o contexto universitário, como um dos responsáveis por permitir a acessibilidade linguística e comunicativa dos surdos. Assim, ao ampliar as perspectivas de trabalho, salientamos a necessidade de compreender os preceitos éticos e a Legislação, que circundam esta profissão, bem como a necessidade de compreensão deste profissional em torno dos processos, estratégias e modalidades que pode seguir durante o processo de tradução-interpretação em diferentes contextos sociais.

Deste modo, nossas reflexões apontam a importância de que o TILS se reconheça como mediador da comunicação entre surdos e ouvintes, para que não sobrecarregue o seu trabalho com as atribuições dos professores regentes. Porque, compreendemos que esta referida sobrecarga pode contribuir para que o TILS não participe de forma plena do processo de tradução-interpretação, o que consequentemente, dificulta na participação dos surdos em espaços majoritariamente ouvinte.

Por fim, no decorrer da pesquisa o que nos chamou atenção foi o envolvimento do trabalho deste profissional, não somente no que diz respeito ao processo de tradução e interpretação na sala de aula, mas sim, geralmente, se confunde com o trabalho do professor 
regente, como se fosse o TILS o principal responsável pelo processo de ensino-aprendizagem das pessoas surdas.

Reiteramos que o referido profissional não é o principal responsável do ensinoaprendizagem das pessoas surdas, mas, o consideramos como co-responsável e de tal importância que sem o TILS, dificilmente seria possível a aprendizagem dos surdos, na maioria das escolas. Por essa via, salientamos a importância do seu trabalho, bem como a necessidade de que professores regentes e TILS trabalhem de maneira cooperativa. Isto é, que as tomadas de decisões em sala de aula em relação aos surdos contem com a participação de ambos profissionais.

Além disto, identificamos também que o trabalho voluntário e o assistencialismo, ainda se fazem presentes no ofício deste profissional. Por esta via, ressaltamos a importância de estes aspectos sejam superados para que o TILS possa se comprometer o máximo possível com o processo de tradução-interpretação, com a finalidade de reafirmar o status de sua profissão.

\section{REFERÊNCIAS}

BRASIL. Decreto $n^{\circ}$ 5.626. Regulamenta a Lei $n^{\circ} 10.436$, de 24 de abril de 2002, que dispõe sobre a Língua Brasileira de Sinais - Libras, e o art. 18 da Lei no 10.098, de 19 de dezembro de 2000. Diário Oficial [da República Federativa do Brasil], Brasília, DF, 2002.

BRASIL. Lei $\mathrm{n}^{\mathrm{o}}$ 10.098, de 19 de dezembro de 2000. Estabelece normas gerais e critérios básicos para a promoção da acessibilidade das pessoas portadoras de deficiências ou com a mobilidade reduzida e dá outras providências. Diário Oficial [da República Federativa do Brasil], Brasília, DF, 2000.

BRASIL. Lei $n^{\circ} 10.436$, de 24 de abril de 2002. Dispõe sobre a Língua Brasileira de Sinais Libras e dá outras providências. Diário Oficial [da República Federativa do Brasil], Brasília, DF, 2002.

BRASIL. Lei $\mathrm{n}^{\circ}$ 12.319. Regulamenta a profissão do tradutor e intérprete da Língua Brasileira de Sinais - Libras. Diário Oficial [da República Federativa do Brasil], Brasília, DF, 2002.

CHIZZOTTI, Antônio. A pesquisa qualitativa em ciências humanas e sociais: Evolução e desafios. Revista Portuguesa de Educação, Braga, Portugal, v. 16, n. 002, p. 221-236. 2003.

GESSER, Audrei. Tradução e interpretação da Libras II. Texto base do curso de bacharelado em letras/Libras: Universidade de Santa Catarina. Florianópolis, 2011. Disponível em: <

http://www.libras.ufsc.br/colecaoLetrasLibras/eixoFormacaoEspecifica/traducaoEInterpretaca oDaLinguaDeSinais/assets/767/Texto_base_TIL_II_2008.pdf >. Acesso em: 03 jan. 2016. 
GESSER, A. Libras? Que língua é essa?: crenças e preconceitos em torno da língua de sinais e da realidade surda. São Paulo: Parábola, 2009.

KELMAN, Celeste Azulay. Os diferentes papéis do professor intérprete. Espaço:

Informativo Técnico Científico, Rio de Janeiro, v. 24, n. 24p. 25-30, 2005.

LACERDA Cristina Broglia Feitosa de. Tradutores e intérpretes de Língua Brasileira de Sinais: formação e atuação nos espaços educacionais inclusivos. Cadernos de Educação. FaE/PPGE/UFPel | Pelotas [36]: p.133 - 153, maio/agosto 2010.Disponível em: < https://periodicos.ufpel.edu.br/ojs2/index.php/caduc/article/viewFile/1604/1487>. Acesso em: 27 jun. 2017.

MINAYO, Maria Cecília de Souza (Org.). Pesquisa social: teoria, método e criatividade. Petrópolis: Vozes, 1993.

QUADROS, Ronice Müller de. O tradutor e intérprete de língua de sinais brasileira e língua portuguesa. Secretaria de Educação Especial/Programa Nacional de Apoio à Educação de Surdos. Brasília: MEC/SEESP, 2004.

RODRIGUES, Carlos Henrique; BEER, Hanna. Os estudos da tradução e da interpretação de línguas de sinais: novo campo disciplinar emergente?. Cadernos de Tradução, Florianópolis, v. 35, n. 2, p. 17-45, out. 2015. ISSN 2175-7968. Disponível em: $<$ https://periodicos.ufsc.br/index.php/traducao/article/view/21757968.2015v35nesp2p17/30707>. Acesso em: 28 jun. 2017.

QUADROS, Ronice Müller de; STUMPF, Marianne Rossi. O primeiro curso de graduação em letras língua brasileira de sinais: educação a distância. ETD - Educação Temática Digital, Campinas, SP, v. 10, n. 2, p. 169-185, out. 2009. ISSN 1676-2592. Disponível em: $<$ https://periodicos.sbu.unicamp.br/ojs/index.php/etd/article/view/984>. Acesso em: 27 abr. 2018.

SANTOS, Ozivan Perdigão. Travessias históricas do tradutor/intérprete de Libras: de 1980 a 2010. Revista do Difere - ISSN 2179 6505, v. 2, n.4, p. 1-16. 2012. Disponível em: < http://www.artificios.ufpa.br/Artigos/ozivan.pdf>. Acesso em: 03 jan. 2016. 